\title{
Highlighting the Importance of Context in the TPACK Model: Three Cases of Non-traditional Settings
}

\author{
Gregory R. MacKinnon \\ School of Education \\ Acadia University
}

\begin{abstract}
This paper presents three cases of technology intervention in classrooms. The TPACK model has long since considered context as a contributing factor in teaching with technology. The teaching settings described herein further demonstrate that context can drive pedagogy, technology and content independently whilst the established interactions of each continues to occur. The analysis of these settings suggests that contextual factors of culture, learning challenges and second language study present additional complexity to the teaching and learning environment, especially as technology is employed to empower learning.
\end{abstract}

Keywords: TPACK model; culture; educational technology; pedagogy; L2

\section{The Evolution of Technology Intervention Studies}

Past modes of research involving technology intervention in classrooms (Thompson, Simonson, \& Hargrave, 1996) often hinged on comparing performance of those students with and without computers in the classroom. An evolving sense of the many uncontrollable variables in such settings, has arguably mitigated valid implications from many studies. This has led to the promotion of more qualitative and mixed methods studies that examine the nuances of the interplay between technology, student and teacher (Selwyn, 1997, 2002; Forsythe \& MacKinnon, 2005; Roblyer, 2005). With this introspection, the development of a model that deconstructed this complex environment was both necessary and timely.

\section{Understanding the Nature of Technology Intervention: The TPACK Model}

The early work of Shulman (1986) served as a basis for a more careful consideration of the synergy between instructor pedagogy and content knowledge. Shulman (2005) further defined the notion of "signature pedagogies," i.e., each content area is associated with

Gregory MacKinnon, PhD is a Professor of Science \& Technology Education at the School of Education, Acadia University, Nova Scotia Canada. Correspondence with the author can be made through gregory.mackinnon@acadiau.ca 
a characteristic range of pedagogies that have historically been plied by educators with success. An example of this might be the use of case studies in law or medicine (Dunn \& Brooks, 2007). Subsequent to this work, several authors have compiled and elaborated on pedagogies that teach students to have the "habits of mind" of professionals in the field (Gurung, Chick, \& Haynie, 2009; Chick, Haynie, \& Gurung, 2012). This has also been extended to consider signature pedagogies which invoke technology (CIS, 2012).

The work of Shulman (1986) has served as foundation for the consideration of technology as a compounding factor in considering the pedagogical-content knowledge interplay in teaching. Since its inception, (Mishra \& Koehler, 2006, 2007) the TPACK (technological, pedagogical, content knowledge) model has garnered considerable attention as a framework for considering the complex interactions of these components as the educator seeks to empower education with technology

\section{TPACK: Revisiting the Importance of Context}

Much has been written (Rosenberg \& Koehler, 2015) about the importance of context in elaborating on the original TPACK model. Porras-Hernández \& Salinas-Amescua (2013) have suggested a model (Figure 1) that emphasizes two dimensions: the scope (macro, mezzo, micro contexts) and the actor (teacher/learner internal contexts). Angeli, Valanides and Christodoulou (2016) elaborate on this model.

Each of these levels includes not only externally given conditions that affect and designate teacher's practice, but also objects of knowledge that

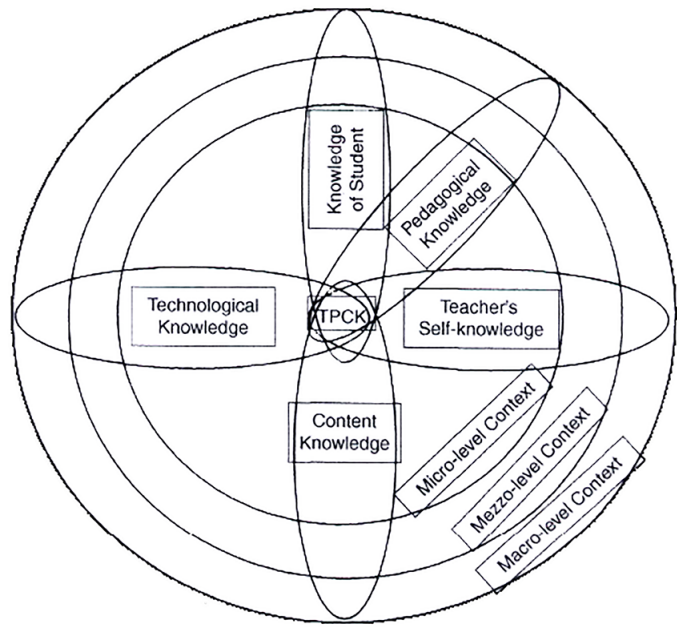

Figure 1, A scope and actor TPACK Model (adapted from Porras-Hernández \& Salinas-Amescua, 2013) the teacher learns to construe. Macro context is defined by social, political, technological, and economic conditions at the global level. Mezzo context is defined by social, cultural, political, organizational and economic conditions settled in the local community and the educational institution. Finally, micro context is the level where teachers enjoy greater independence and deals with in-class conditions for learning (e.g., available resources, norms and policies, beliefs, expectations, teachers' and students goals). (p. 18)

Benton-Borghi $(2013,2016)$ has offered an extended model that integrates the concept of universal design for learning (hereafter UDL). This is a particularly useful framework because it takes into account the contexts of all learners while giving due emphasis to those that may have learning challenges (see Figure 2). 


\section{How Context Might Drive TPACK}

Most proponents of TPACK will agree that the teacher's pedagogy should strongly influence what technologies they choose to invoke in an effort to empower learning. One might also argue that the nature of the content may also drive the technology choices teachers make. The following discussion introduces three unique teaching-learning environments where it should be evident that context has the potential to greatly influence the success of technology intervention. These cases support an argument that much more work must be done to identify and account for a broad range of contexts in applying the TPACK model, especially for non-traditional learners. These examples

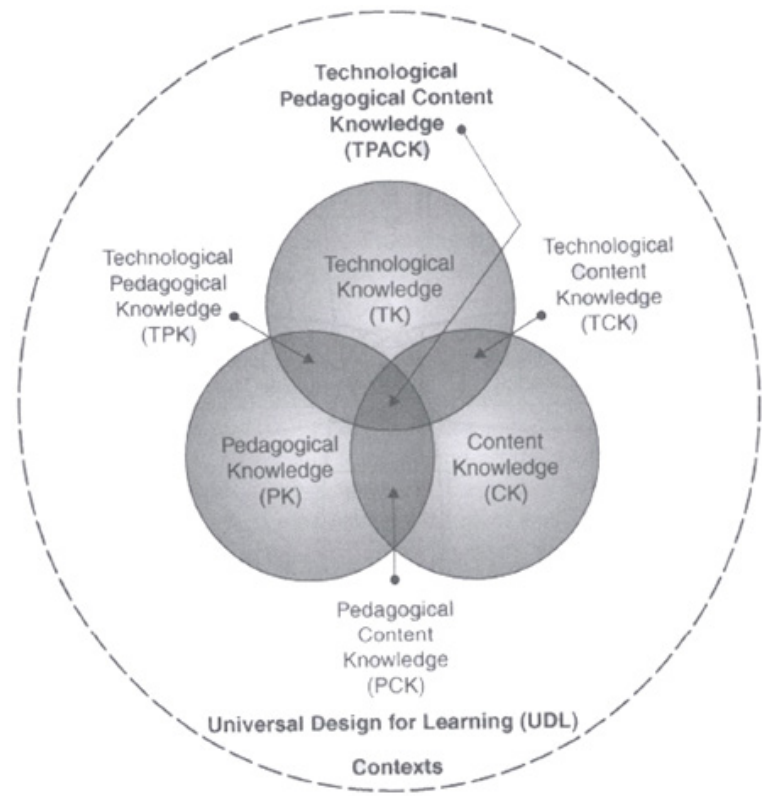

Figure 2, A UDL TPACK model (adapted from BentonBorghi. 2013) were chosen specifically from the research of the author and are not intended to be comprehensive in representing the many contexts that TPACK could be applied.

\section{Multimedia Cases and Sports Therapy}

At a small liberal arts university in North America, a faculty member used Adobe Acrobat to create a group of sports injury case studies online. These cases made use of video, digital anatomical manipulatives and hyperlinked resources. Being a laptop university (MacKinnon, 2007), students necessarily had laptop computers in multimedia-rich classrooms, so access to the cases synchronously and asynchronously was facile. As an action research project in his own classroom, the undergraduate instructor undertook to research the variables that impacted the successful implementation of this technology as per the feedback from his student stakeholders (MacKinnon \& King, 2012; Beaulieu, 2013).

The findings of the North American study indicated that students wanted 1) more input from the instructor in terms of deconstructing a case, 2) more practice with a range of cases and 3) more partnering/team approaches to practice hands-on manipulation of injured anatomy.

Based on the feedback from students, the instructor modified both the hybridized teaching model as well as the technology itself. In order to establish some generalizability of the intervention, the updated tool was implemented with the assistance of an instructor in an undergraduate sports science program in Kingston, Jamaica (see Figure 3). It was anticipated that there may be cultural differences that mitigate the impact by comparison to the North American pilot trial, so a mixed method research study was undertaken (King, Lawrence \& MacKinnon, 2014) 


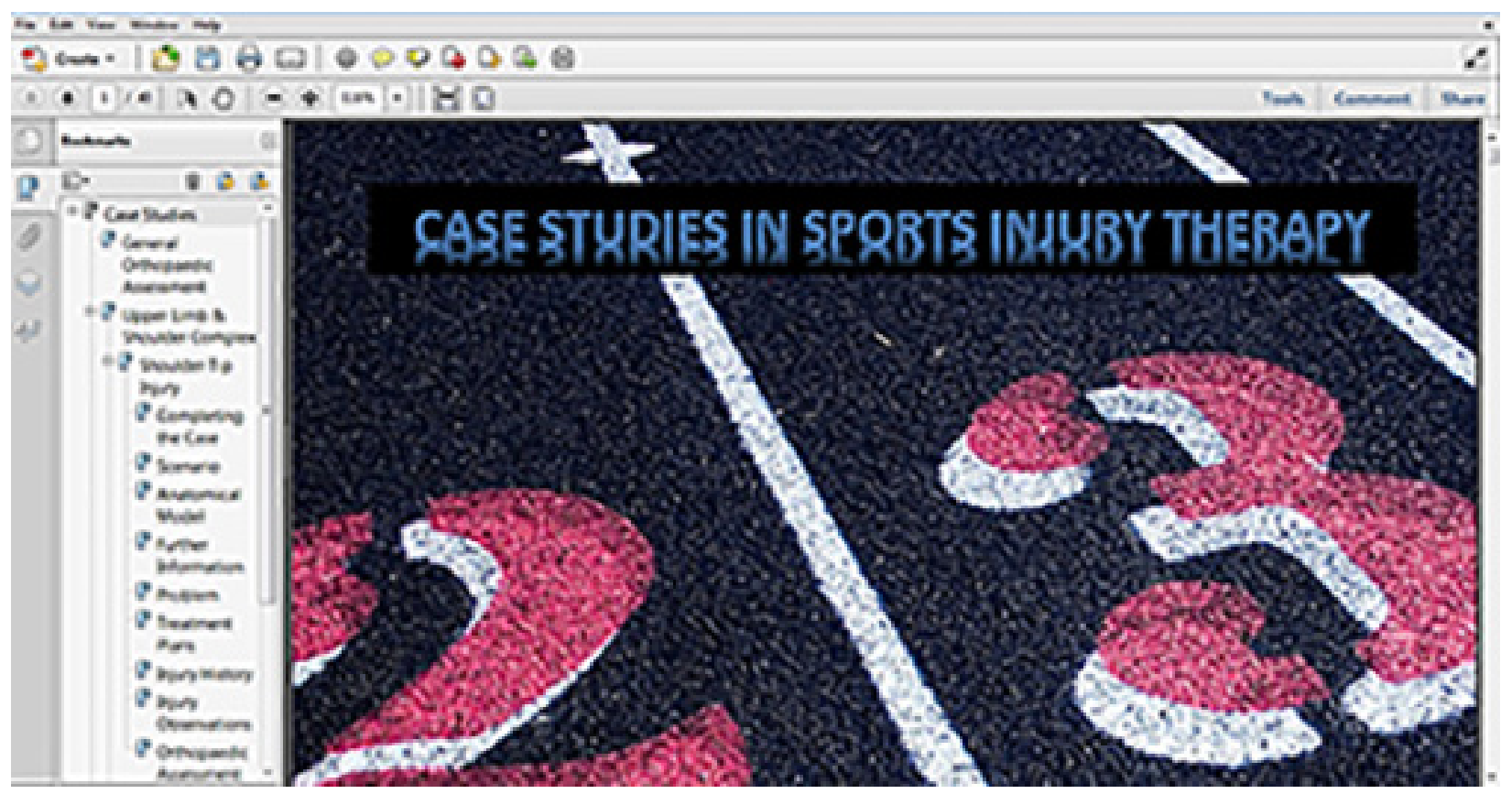

Figure 3, Sports science case study tool: Using an Acrobat ${ }^{\circledR}$ framework

\section{TPACK: Understanding Cultural Differences in Technology Intervention}

In changing contexts for implementation, there were a number of observations that arose from the research, and the discussion of each follows. The use of an online format was highly ineffective given that the bandwidth in developing countries such as Jamaica is limited. This constraint limited the "just in time" learning (Halverson \& Collins, 2009) that could be accessed as students worked their way through cases on and off campus. This prompted the use of DVDs in the short term with a plan to make the pdf file accessible through a phone application. In this learning context, the best access to computers was on campus given that most students were not affluent enough to own computers; this was decidedly different from the North American setting. This digital divide (Rice, 2003) then seriously impacted the desired pedagogical model which was reliant to some extent on both seamless classroom use as well as asynchronous self-led study.

Despite advanced preparation of the Jamaican instructor in both use of the technology and the implied pedagogy, there were context dependent impediments. In many developing countries (especially colonized regions), the teaching models remain quite traditional. The notion of student-centred constructivist learning (Brooks \& Brooks, 1993) is something many have read about but relatively few practice in certain Caribbean settings (CDB 2015). Couple this with decided differences in how the process or protocol of injury assessment and treatment is undertaken, and the study of this technology intervention became increasingly difficult. The use of concept mapping to clarify the relationships between component and over-arching themes was of little use to either the instructor or 
the students, as they were unfamiliar with this graphic articulation of content and process knowledge. Whereas the technology may have proven useful, the lack of integration into a viable hybridized constructivist teaching model was problematic.

Many students in this context found the access to digital anatomical models (see Figure 4) very useful for analyzing sites of injury. Quite predictably though, the choices of injury sports were somewhat irrelevant. Whereas North American students could relate to baseball, football and tennis injuries, this content was less suitable in the Caribbean, where cricket and track sports were more recognizable. One might make the argument that the content impacted the motivation to access the technology and further the pedagogical mode of student's independent learning.

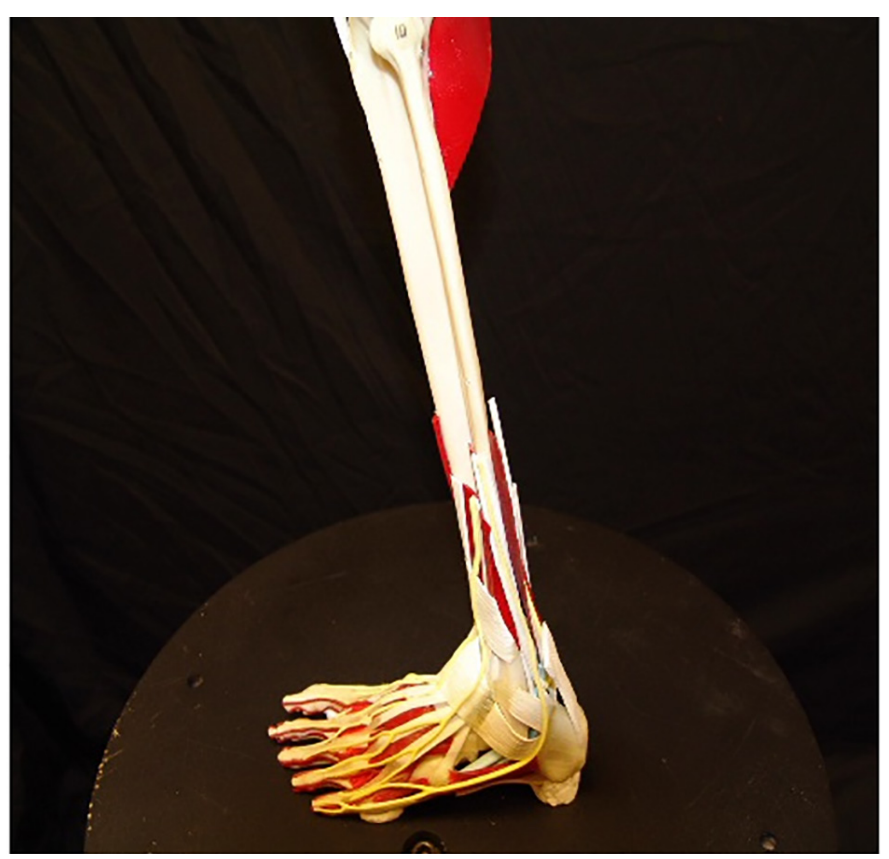

Figure 4, Anatomical models: Real time digital manipulatives

\section{Creating a Digital Dictionary for the Deaf in Jamaica}

American Sign Language (ASL) is the standard for communication in many countries; however, Jamaican children are much more likely to learn a variation known as Jamaican Sign Language (JSL) (Dolman, 1986).

In Jamaica, there are upwards of 650 deaf students across 13 specialized schools, coordinated by the Jamaican Association of the Deaf (hereafter JAD). Those deaf students, 16-18 years of age, are estimated by the organization to have a literacy level of grade 4. Providing communication resources is a crucial step in assisting these children to take a productive role in Jamaican society. This is particularly relevant when one considers the undeniable causal relationship between disability and poverty (Gayle-Geddes, 2015).

In the past, JAD has supported the hearing impaired in the country by creating a paperbased dictionary composed of prepared photographs of signed words and sentences. These photographs were added to a digital database for possible future use. Recently JAD has capitalized on the ease of Adobe Acrobat $\AA$ to create a searchable digital database of pictures and text captions of words (MacKinnon \& Soutar, 2015). The emergence of readily accessible digital video has further allowed JAD to pursue the creation of video clips of signed words in various categories of relevance to school children. 


\section{TPACK: How It Helped to Understand the Deaf Classroom Context}

In this project, the progression from a paper-based dictionary to a digital dictionary has been driven by available technologies. The research on these systems (MacKinnon \& Soutar, 2015) has revealed that the stakeholders appreciate clearer photographs in the digital format in comparison to the paper-based dictionary. Furthermore, the evolution to video has had a tremendous impact on users. The fine articulation of hand and digit movements in signing difficult words is made exponentially easier to perceive by using high resolution video from multiple angles. In this way, the technology empowers the pedagogy and arguably improves access to content knowledge.

While initially the promise of housing the digital dictionary online was inviting, it became evident that the bandwidth for pictures and videos was insufficient for reasonable access. This is what prompted the use of a DVD with the Acrobat ${ }^{\circ}$ file housed on it. This, of course, presumes access to disk drives on either school or home computers. Most school computers in this developing-country context were relatively old, so disk drives were quite common. However, the assumption that children would have home computers was erroneous. There is an inextricable link between disability and poverty; many homes were not able to afford computers of any description, so this precluded parental use of the resource. This has since prompted a reconsideration of the appropriate technology. Given that parents of deaf children would be more likely to have mobile phones, this has led to the ramping up of efforts to create a mobile phone app that would house the dictionary.

Feedback from users has suggested that there is adequate technological ability to retrieve information from the digital dictionary in the current DVD format. Furthermore, the teachers that piloted the DVD digital dictionary exhibited a positive predisposition to instructional technologies.

In interviews, it was evident that teachers possessed good content knowledge. The pedagogical knowledge was clearly linked to strategies for teaching and learning with deaf children. It was also observed that many of these focused approaches were neither student-centered or constructivist in nature (Brooks \& Brooks, 1993). This was a problematic situation in that the designers presumed that the technology would empower good teaching practice. The pedagogical content knowledge was adequate but certainly traditional by all measures.

The project was instructive because it underlined the importance of regular stakeholder input in technology formulation, an ideal proposed some time ago in instructional design models such as R2D2 (Willis \& Wright, 2000). When classrooms were visited, it became obvious that that technological pedagogical knowledge was a challenge. The pilot study of the digital dictionary revealed that teaching in classrooms of deaf children was decidedly different from mainstream education. The teachers had access 
to some computer labs for use of the dictionary, but the notion that the dictionary might be integrated seamlessly into classroom practice (possibly through use of the teacher's laptop or student computers) was totally unrealistic given the context of the schools. The teachers not only needed professional development in child-centred teaching, but they also had no idea how they would integrate the use of the dictionary into their ongoing teaching practice.

The context in this case posed constraints through the digital divide, in terms of lack of access to the technology (Rice, 2003; White, 2007). More importantly, the pedagogy required significant development with respect to international best practice, both with and without the digital dictionary technology (Dede, 2005, 2007; Dobbins, 2005).

\section{Designing and Implementing Progressive Curriculum in China: A STEM Case Study}

In an effort to invoke a curriculum that reflected international trends, a new p-9 private School in Shanghai, China has embarked on the development of integrated Science, Technology, Engineering and Mathematics (hereafter STEM) curriculum. A case study (MacKinnon, Greene, Rawn, Cressey \& He, 2017), based on the implementation of a compilation of 16 STEM activities in a grade 6 classroom with 19 students, was completed. The activities were based on a mapping of science and mathematics outcomes, by textbook chapter, onto the national curriculum. The curriculum design aligned with the approach of Sanders (2009) when he suggested, "Our notion of integrative STEM education includes approaches that explore teaching and learning between/among any two or more of the STEM subject areas, and/or between a STEM subject and one or more other school subjects" (p. 21). Further, the format adopted his notion that activities should "provide a context and framework for organizing abstract understandings of science and mathematics and encourage students to actively construct contextualized knowledge of science and mathematics, thereby promoting recall and learning transfer" (p. 23). STEM activities were designed around principles of social constructivism, situated cognition and problem-based learning (Carr, Jonassen, Litzinger, \& Marra, 1998). They necessarily involved hands-on student centered learning which often relied on building models, engaging online simulations, electronic probes and graphical analysis as well process skills such as estimation, prediction and analysis. Within this framework, the practice of "just in time" learning was favored over "just in case" learning (Halverson \& Collins, 2009).

\section{TPACK: Understanding the ESL Context}

Predictably, pedagogical knowledge in the area of English as a Second Language was an extension of traditional approaches. While many of the teaching and learning strategies had elements of constructivist pedagogy, the teacher had to also draw on STEM content, which would necessarily have its own signature approaches. Clearly, applying the TPACK 
framework becomes increasingly complex when one tries to blend language learning and STEM outcomes. One could argue that teaching vocabulary and conversational approaches through the vehicle of STEM content could certainly be achieved, but it is important not to overlook what might be distinctly different inherent pedagogies.

Students in this pilot study were exposed to STEM classes once per week for one hour after their regular mathematics and science courses. The study identified the importance of coordinating both core curriculum and core teacher support with the STEM course offering.

Aligning the curriculum content areas for students improved the relevance of the core courses and defined the STEM experience as an applied exercise. Even though the STEM course was not assessed through standardized testing (as were the core courses), preliminary feedback was that retention of fundamental concepts was improved because of the STEM course. Given the practical nature of the STEM content, access to handson materials was presumed. Readily accessible materials in China did not necessarily align with those common in other countries, such that the proposed activity content and pedagogy were mitigated or at least modified substantially in some cases. Lastly, the content of the courses necessitated a teacher with a broad background in linguistics as well as STEM foundations.

While teacher preparation for "teaching with technology" was deemed good with a predisposition to try potentially empowering technologies, the use of technologies to support a constructivist learning environment was quite foreign to the students. This was primarily due to a predominant and lingering adherence to traditional teachercentered pedagogies and was exacerbated by the perceived notion (of administrators, teachers, parents and children) that the most efficient instructional approach to mastering standardized assessment was decidedly a transmission model of lecture. Applying such strategies as cooperative learning and higher order thinking (as defined by Bloom, Engelhart, Furst, Hill, \& Krathwohl, 1956) were particularly challenging; this made technology intervention a more uncomfortable fit for students in the classroom.

Due to lack of accessible classroom computers, the default use of technology for the teacher in this pilot was to digitally project: simulations, discrepant event videos, computer probe collection data and media. Despite concerns about the perceived lack of national assessment of such learning, students found the use of technology in learning to be motivational. Because of students' inherent interest in technology, the teacher found that casual home assignments/investigation that tapped into unique software experiences were quite popular with students. Access to computers at home was not a problem due to the demographic of students attending this private school.

In this case study, the biggest deterrent to STEM curriculum implementation dealt with pedagogical content knowledge. In exercises that promoted critical thinking and frequent teacher-student Socratic and negotiative interplay, relational and deconstructive language such as compare, contrast hypothesize, synthesize, etc., were very difficult for 
students to understand. As a result, these instructional phrases directly affected the pedagogy that could be used to interrogate the concepts.

\section{What Do These Cases Tell Us About The TPACK Model?}

The TPACK model has enjoyed much fruitful use in both analyzing classrooms interventions and designing comprehensive studies of technology use in classrooms (Herring, Koehler, \& Mishra, 2016). Researchers Angeli, Valanides, and Christodoulou (2016) have suggested that the existing TPACK framework is all-inclusive in its scope. In applying the TPACK model to a greater range of settings, some researchers (PorrasHernández \& Salinas-Amescua, 2013; Benton-Borghi, 2013, 2016) have seen a need to emphasize the contextual implications of the model. It might be argued that the current literature has not adequately examined the non-traditional classroom setting as it relates to the complexity that context potentially invokes. The three cases alluded to above press the TPACK model in unique ways. It prompts the question of how the current TPACK framework accounts for differences in culture, learning challenges and second language instruction. The cases above would suggest that the context of the technology intervention could drive any or all of the TPACK components, namely pedagogy, content knowledge and technology (Figure 5). Using a plant metaphor, one could posit the notion that $\mathrm{T}, \mathrm{P}$ and $\mathrm{CK}$ actually grow out of and are simultaneously constrained by the possibilities that the context affords. So, while the TPACK model, in its formulation, accounted for

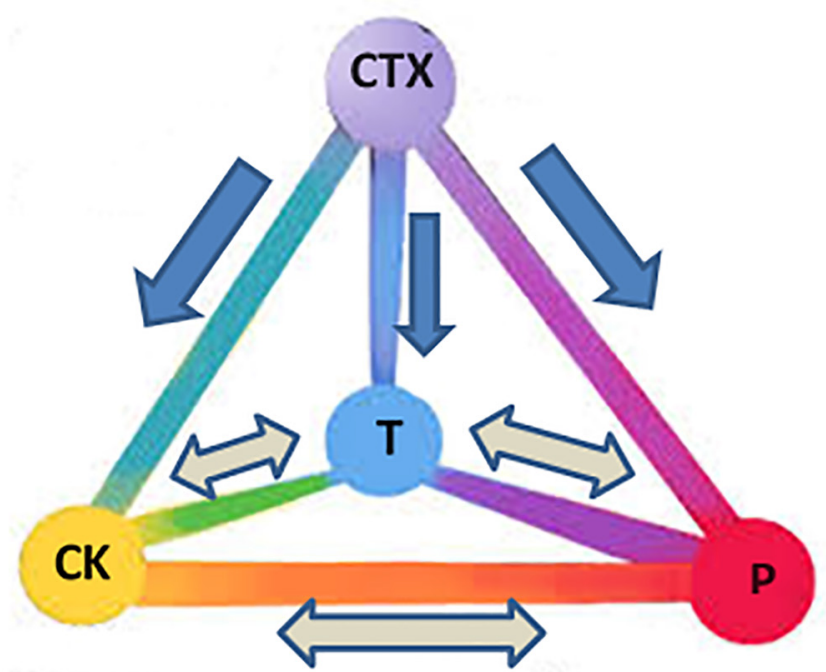

Figure 5. Context driving the TPACK model. CTX represents context, CK represents content knowledge, $\mathrm{P}$ represents pedagogy and $T$ represents technology context, each and every example of research on non-traditional teaching and learning settings helps us to better understand the scope of its application. The sheer volume of contextual studies (Rosenberg \& Koehler, 2015) assists us in refining the TPACK model's application and its inherent limitations 


\section{References}

Angeli, C., Valanides, N., \& Christodoulou, A. (2016). Theoretical Considerations of Technological Pedagogical Content Knowledge. Handbook of Technological Pedagogical Content Knowledge (TPACK) for Educators, $2^{\text {nd }}$ Ed. 11-32.

Beaulieu, R. (2013). Action research: Trends and variations. Canadian Journal of Action Research, 14(3), 29-39.

Benton-Borghi, B. H. (2013). A Universally Designed for Learning (UDL) infused Technological Pedagogical Content Knowledge (TPACK) practitioners' model essential for teacher preparation in the 21st Century. Journal of Educational Computing Research, 48(2), 245-265.

Benton-Borghi, B. H. (2016). Universal Design for Learning (UDL) Infused Technological Pedagogical Content Knowledge (TPACK) Model Prepares Efficacious 21stCentury Teachers. Handbook of Technological Pedagogical Content Knowledge (TPACK) for Educators, 143.

Bloom, B.S. (Ed.). Engelhart, M.D., Furst, E.J., Hill, W.H., Krathwohl, D.R. (1956). Taxonomy of educational objectives, handbook I: The cognitive domain. New York: David McKay Co Inc.

Brooks, J. G., \& Brooks, M. G. (1993). The case for constructivist classrooms. Alexandria, VA: Association for Supervision and Curriculum Development.

Carr, A. A., Jonassen, D. H., Litzinger, M. E., \& Marra, R. M. (1998). Good ideas to foment educational revolution: The role of systemic change in advancing situated learning, constructivism and feminist pedagogy. Educational Technology, 5-15.

CDB (2015). The evaluation of the Caribbean development bank's intervention in technical and vocational education and training (1990-2012). Retrieved from: http://www.caribank.org/wpcontent/uploads/2015/05/CompleteTVETReport.pdf

Chick, N.L., Haynie, A., Gurung, R.A.R. (2012). Exploring more signature pedagogies: approaches to teaching disciplinary habits of mind. Virginia: Stylus.

CIS (2012). Signature pedagogies incorporating technology. Computers in Schools 29 (1-2). (special issues)

Dede, C. (2005). Planning for neomillenial learning styles: Implications for investments in technology and faculty. In Educating the net generation. D. Oblinger \& J. Oblinger (Eds.) Boulder, CO: EDUCAUSE 
Dede, C. (2007). Introduction: A sea of change in thinking, knowing, learning \& teaching In Salaway, G. \& Borreson Caruso, J. The ECAR study of undergraduate students and information technology. Boulder, CO EDUCAUSE

Dobbins, K. (2005). Getting ready for the net generation. EDUCAUSE Review, 40(5), 8-9.

Dolman, D. (1986). Sign languages in Jamaica. Sign Language Studies, 52(1), 235-242.

Dunn, D. \& Brooks, K. (2007). Teaching with cases. Halifax, NS: Society for Teaching \& Learning in Higher Education.

Forsythe, T. \& MacKinnon, G. (2005) Technology \& cooperative learning: The IIT model for teaching authentic chemistry curriculum. In R. Yager, Exemplary science in grades 9-12: Standards-based success stories (pp. 11-23.). Arlington, VA: NSTA Press.

Gayle-Geddes, A. (2015). Disability \& inequality: Socioeconomic imperatives and public policy in Jamaica. New York, NY: Palgrave MacMillan

Gurung, R. A., Chick, N. L., \& Haynie, A. (2009). Exploring signature pedagogies: Approaches to teaching disciplinary habits of mind. Virginia: Stylus Publishing.

Halverson, R. \& Collins, A. (2009). Rethinking education in the age of technology. The digital revolution and schooling in America. New York: Teachers College Press.

Herring, M. C., Koehler, M. J., \& Mishra, P. (Eds.). (2016). Handbook of technological pedagogical content knowledge (TPACK) for educators. Routledge.

King, C., Lawrence, L., \& MacKinnon, G. (2014). Using multimedia technology in Jamaican athletic training education: A case based learning approach. Journal of Applied Learning Technology 4(2), 40-48.

MacKinnon, G. \& King, C. (2012). A Sports injury case study model: Capitalizing on virtual reality technology. Journal of Sports Science \& Technology 12(1), 117128.

MacKinnon, G. \& Soutar, I. (2015) Creating a Digital Jamaican Sign Language Dictionary: A R2D2 Approach, Computers in the Schools, 32, 224-239.

MacKinnon, G. Greene, K., Rawn, E. Cressey, J. \& He, W. (2017). Employing STEM curriculum in an ESL classroom: A Chinese case study. K-12 STEM 3(1), 143155.

Mishra, P., \& Koehler, M. (2006). Technological pedagogical content knowledge: A framework for teacher knowledge. Teachers College Record, 108(6), 1017-1054. 
Mishra, P. \& Koehler, M.J. (2007). Technological Pedagogical Content Knowledge (TPACK): Confronting the Wicked Problems of Teaching with Technology. In R. Carlsen, K. McFerrin, J. Price, R. Weber \& D. Willis (Eds.), Proceedings of Society for Information Technology \& Teacher Education International Conference 2007 (pp. 2214-2226). Chesapeake, VA: Association for the Advancement of Computing in Education (AACE).

Porras-Hernández, L. H., \& Salinas-Amescua, B. (2013). Strengthening TPACK: A broader notion of context and the use of teacher's narratives to reveal knowledge construction. Journal of Educational Computing Research, 48(2), 223-244.

Rice, M. F. (2003). Information and communication technologies and the global digital divide: Technology transfer, development, and least developing countries. Comparative Technology Transfer and Society, 1(1), 72-88.

Roblyer, M. D. (2005). Educational technology research that makes a difference: Series introduction. Contemporary Issues in Technology and Teacher Education [Online serial], 5(2). Retrieved from http://www.citejournal.org/volume-5/issue-2-05/ seminal-articles/educational-technology-research-that-makes-a-differenceseries-introduction

Rosenberg, J. M., \& Koehler, M. J. (2015). Context and technological pedagogical content knowledge (TPACK): a systematic review. Journal of Research on Technology in Education, 47(3), 186-210.

Sanders, M. (2009). Stem, stem education, stemmania. The Technology Teacher (Dec/ Jan) 20-26.

Shulman, L. S. (1986). Those who understand: Knowledge growth in teaching. Educational researcher, 15(2), 4-14.

Shulman, L. S. (2005). Signature pedagogies in the professions. Daedalus, 134(3), 5259.Retrieved from http://gse.buffalo.edu/gsefiles/documents/about/Signaturepedagogies-in-the-professions.pdf

Selwyn, N. (1997). The continuing weaknesses of educational computing research. British_Journal of Educational Technology, 28(4), 305-307.

Selwyn, N. (2002). Telling tales on technology: Qualitative studies of technology and education. Burlington VT: Ashgate.

Thompson, A., Simonson, M. \& Hargrave, C. (1996). Educational technology: A review of the research. Washington, DC: Association for Educational Communications and Technology. 
White, S. (2007). Mapping the global digital divide. International Journal of Business Information Systems 7(2), 1-19.

Willis, J., \& Wright, K. E. 2000, A general set of procedures for constructivist instructional design: The new R2D2 model. Educational Technology 40(2), 5-20. 